\title{
SER PROTAGONISTA - QUÍMICA: UMA ANÁLISE DO VOLUME 3 COM FOCO EM SUAS ANALOGIAS
}

\author{
SER PROTAGONISTA - QUÍMICA: AN ANALYSIS OF VOLUME 3 FOCUSING ON ITS \\ ANALOGIES
}

Márcia Jayane Nascimento Machadoํㅜ , José Ossian Gadelha de Lima²

Recebido: fevereiro/2021 Aprovado: abril/2021

\begin{abstract}
Resumo: Constituindo-se no principal instrumento utilizado por professores no planejamento e desenvolvimento de sua prática pedagógica, o livro didático comumente utiliza estratégias de ensino chamadas de 'analogias' no tratamento de conceitos difíceis de serem compreendidos. Apesar do vasto uso em sala de aula, muitos trabalhos têm destacado a importância de um olhar mais crítico sobre as potencialidades e limitações do raciocínio analógico como recurso de mediação didática. Assim, o objetivo deste trabalho foi mostrar os resultados de um estudo crítico acerca dos aspectos organizacionais do volume 3 da coleção 'Ser protagonista - Química', adotado no Ensino Médio, destacando uma apreciação sobre as analogias nele presentes. Com a leitura integral e criteriosa da obra, identificação, classificação e discussão dos elementos de interesse, os resultados apontaram aspectos positivos e negativos na organização do exemplar. Pudemos observar uma baixa frequência de analogias no livro, predominando as do tipo simples. Este estudo revelou ainda a importância e eficácia da análise reflexiva durante o processo de escolha dos manuais didáticos e também dos raciocínios analógicos, comumente empregados pelos autores de livros e pelos docentes em sala de aula.
\end{abstract}

Palavras-chave: Livro didático. Analogias. Ensino de Química.

\begin{abstract}
Regarded as main instrument used by teachers in planning and developing their pedagogical practice, the textbook commonly uses teaching strategies called 'analogies' when dealing with concepts whose understanding is difficult. Although they are widely used in the classroom, many works have highlighted the importance of a more critical eye over the potential and limitations of these didactic mediation resources. Thus, the aim of this work was to show the results of a critical study on the organizational aspects of volume 3 of the collection 'Ser protagonista - Química', used in the high school, highlighting an analysis of the analogies which it presents. With the whole and careful reading of the textbook, identification, classification and discussion about the elements of interest, the results showed positive and negative aspects in its structuring. We observed a low frequency of analogies in this book, with those of the simple type predominating. This study also revealed the importance and effectiveness of a reflective analysis during the process for choosing textbooks and also analogical reasoning, commonly used by book authors and teachers in the classroom.
\end{abstract}

Keywords: Textbook. Analogies. Chemistry teaching.

\section{Introdução}

O livro didático (LD) é uma ferramenta intencionalmente estruturada com o propósito de colaborar para a eficácia dos processos de ensino e aprendizagem, ou seja, auxiliar tanto aqueles que o utilizam como fonte de aquisição de conhecimento como aqueles que o usam para preparar suas aulas. É dentro desse universo gráfico, rico em textos, esquemas, imagens, cores

https://orcid.org/0000-0003-0155-5895- Graduada em Química pela FAEC/UECE. Rua Penha Marques, 186, casa, Bairro Centro, Cep.63740-000, Novo Oriente, CE, Brasil.E-mail: marcia.machado@aluno.uece.br

2 (iD) http://orcid.org/0000-0003-2423-3645 - Doutor pela UFMG. Professor da FAEC/UECE, Crateús, Ceará, Brasil. Rua Juarez Távora, 132, casa, Bairro São Vicente, Cep.63700-330, CE, Brasil. E-mail: jose.lima@uece.br 
e exemplos, que algumas estratégias de ensino, como as analogias por exemplo, são empregadas com a finalidade de facilitar a compreensão e a aquisição dos conhecimentos nele contidos (LIMA; SILVA, 2010).

Por sua enorme influência no processo educacional formal, o LD constitui uma importante ferramenta, se não a única, utilizada por professores de Ensino Médio para programar e ministrar suas aulas. Desse modo, torna-se imprescindível que a escolha desse instrumento seja feita de forma criteriosa e reflexiva, considerando diferentes aspectos relacionados à sua abordagem didática. Como principal agente responsável por esse processo, o professor deve assumir uma postura crítica diante dessa avaliação, que será determinante para a sua tomada de decisão ao escolher o LD que adotará (FREITAS; RODRIGUES, 2008).

No entanto, Miranda e Lima (2016) observam que há poucos trabalhos na literatura abordando a associação das temáticas 'formação de professores' e 'escolha do livro didático'. Os autores puderam verificar uma quase inexistência, durante os cursos de licenciatura trabalhados em sua investigação, de momentos formativos que fossem capazes de propiciar ao futuro professor um contato sedimentado com os 'saberes docentes' envolvidos no processo de seleção dos LD.

Frison et al. (2009) destacam que o processo de seleção e utilização do LD é um assunto bastante complexo e, por isso, precisa ser debatido, principalmente durante a formação docente, uma vez que demanda o estabelecimento de critérios que instrumentalizam o procedimento de escolha e impulsionam a discussão sobre os processos de ensino e aprendizagem. Visto que o emprego de raciocínios analógicos em manuais didáticos, em particular nos de Química, constitui um fator significativo para a determinação da qualidade dessas obras, pois têm grande relevância na construção efetiva da aprendizagem, torna-se extremamente importante um aprofundamento nas discussões sobre a temática.

Essa demanda se faz necessária devido ao fato de ser corriqueira, no Ensino de Química e das outras Ciências da Natureza, a utilização de estratégias que visam facilitar o processo de apropriação do conhecimento científico. Nesse sentido, as analogias são vistas como excelentes ferramentas mediadoras da aprendizagem, já que permitem ao aprendiz estabelecer uma comparação clara entre duas áreas de conhecimento que não apresentam uma relação íntima entre elas, pelo menos aparentemente. Por isso, torna-se imprescindível que uma analogia realmente eficiente inclua, pelo menos, um componente integrante do conhecimento prévio do educando (saber comum), à medida que o outro é visivelmente desconhecido (saber científico) (ALMEIDA, 2020).

Na literatura especializada, há várias acepções empregadas para o termo 'analogia'. Entre as mais disseminadas está a de Duit (1991), que define uma analogia como uma comparação, baseada em similaridades, entre estruturas de dois domínios diferentes. Entretanto, como afirma Duarte (2005), para que uma analogia seja um instrumento padrão útil ao ensino e ao aprendizado, ela deve de um lado constituir-se de um conteúdo que é familiar aos alunos e, portanto, conhecido, e de outro de um assunto que é pouco conhecido ou totalmente desconhecido por eles. Thiele e Treagust (1994) atribuem ao conceito conhecido o nome de 'domínio da analogia', e o conceito desconhecido denominam de 'domínio alvo'. 
Contudo, como qualquer outra estratégia usada em uma metodologia de ensino, o emprego de analogias, seja por autores de LD ou pelo professor, requer muito cuidado. $\mathrm{Na}$ literatura há vários trabalhos apontando para as vantagens e desvantagens da utilização de analogias como recursos didáticos (CURTIS; REIGELUTH, 1984; DUIT, 1991; THIELE; TREAGUST, 1994; MÓL, 1999; GERHARDT; SILVEIRA, 2009; FRISON et al., 2009). Entretanto, as desvantagens apresentadas por esses diversos autores não implicam na impossibilidade de seu uso. Pelo contrário, os resultados dessas investigações alertam para a necessidade de uma consciência reflexiva sobre os riscos na utilização de analogias, tanto pelos autores de LD quanto pelos próprios docentes, a fim de erradicar, ou pelo menos minimizar, os prejuízos apresentados por essas ferramentas (MONTEIRO; JUSTI, 2000).

Fundamentado nessas conjecturas, o objetivo deste trabalho é apresentar os resultados obtidos a partir de uma investigação acerca dos aspectos organizacionais gerais e das analogias presentes no volume 3 da coleção 'Ser Protagonista - Química', organizada por Murilo Tissoni Antunes ( $2^{\mathrm{a}}$ edição, 2014), concebida, desenvolvida e produzida pelas Edições SM de São Paulo. Contendo 407 páginas, a obra é destinada aos alunos do $3^{\circ}$ ano do Ensino Médio e aborda conteúdos referentes à Química Orgânica (LISBOA et al., 2014).

A escolha desse livro para o desenvolvimento da pesquisa se deu em razão de se tratar de uma das obras incluídas no PNLD (Programa Nacional do Livro Didático) desde 2012, sendo, portanto, uma das coleções mais adotadas no Ensino de Química desenvolvido nas Escolas de Ensino Básico do Brasil (BRASIL, 2011). Além disso, é o livro mais adotado pelas escolas da região onde este trabalho foi desenvolvido. Enquanto licenciandos e futuros professores, precisamos aprender a selecionar o LD a ser adotado em nossa prática profissional futura, o que implica em uma necessidade imprescindível a prática de saber analisar criticamente a obra que servirá de apoio ao aprendizado de nossos alunos (MORTIMER, 1988).

\section{Metodologia}

Com relação à finalidade, essa pesquisa pode ser classificada como do tipo exploratória pois, como afirma Gerhardt e Silveira (2009, p. 35), “[...] esse tipo de pesquisa tem como objetivo proporcionar maior familiaridade com o problema, com vistas a torná-lo mais explícito ou a construir hipóteses". Neste caso, o propósito deste trabalho está fundamentado na identificação, análise, classificação e discussão dos raciocínios analógicos empregados no LD analisado, caracterizando-se, portanto, como uma análise de cunho qualitativo (MALHEIROS, 2011).

Para a realização desta pesquisa estabelecemos, inicialmente, uma dinâmica metodológica que se desenvolveu por meio de algumas etapas. A primeira consistiu no levantamento bibliográfico sobre a problemática estudada, possibilitando-nos identificar e selecionar as principais referências e trabalhos a ela relacionados.

Na segunda etapa, realizamos o reconhecimento da obra analisada e, em seguida, iniciamos a sua leitura integral e criteriosa, a fim de analisar os aspectos didático-organizacionais e identificar as analogias nela presentes. Para essa identificação, selecionamos passagens do 
texto que estavam de acordo com as definições de analogia apresentadas pelos principais pesquisadores da área (CURTIS; REIGELUTH, 1984; DUIT, 1991; THIELE; TREAGUST, 1994; MÓL, 1999) ou quando verificávamos o emprego de orientações pré-tópicos, evidenciadas por Francisco Junior (2009) em seu trabalho, como indicadoras da presença de analogias.

Em um terceiro momento, após finalizarmos a leitura integral da obra, analisarmos as suas características pedagógicas e identificarmos as analogias nela existentes, iniciamos as discussões e reflexões geradas a partir dos dados coletados. Para finalizar esse momento, efetivamos o processo de classificação desses instrumentos analógicos, utilizando para isso um sistema de dez categorias estabelecidas por Thiele e Treagust (1994), adaptadas e descritas por Francisco Junior (2009), Monteiro e Justi (2000), Dias (2014) e França (2017).

A última etapa consistiu na discussão das analogias classificadas e na organização dos resultados obtidos, culminando na elaboração do relatório de pesquisa no qual consideramos diversas temáticas e elementos pertinentes ao LD analisado e ao uso das analogias nele presentes no Ensino de Química. Neste relatório, também discutimos os resultados referentes à análise crítica realizada sobre a obra.

\section{Resultados e discussão}

As características analisadas estão relacionadas tanto a elementos organizacionais quanto conceituais e didáticos presentes na obra. Desse modo, o estudo realizado teve a finalidade de identificar os principais aspectos positivos e negativos que estão diretamente associados à sua elaboração e construção.

O primeiro aspecto analisado nessa investigação se refere ao conteúdo apresentado. Como mencionamos no início deste trabalho, o volume 3 da coleção 'Ser protagonista Química' se destina aos alunos do $3^{\circ}$ ano do Ensino Médio e apresenta conteúdos da área da Química Orgânica. Ocorrendo com uma certa frequência, alguns assuntos tratados na obra fazem alusão à disciplina de Biologia, principalmente aqueles referentes à aplicação dos compostos orgânicos relacionados à vida e à alimentação. Além disso, comumente os autores fazem referência aos mais variados setores da sociedade: agrícola, industrial, farmacêutico e de combustível.

Contudo, uma característica que nos chamou a atenção é a superficialidade na abordagem dessas temáticas, tratando de maneira insignificante o aspecto interdisciplinar da Química e, portanto, subestimando a capacidade de um aprendizado mais amplo e diversificado por parte dos estudantes. Soma-se a isso o fato de a obra não buscar trabalhar os conhecimentos prévios dos alunos, ignorando, praticamente, os saberes que eles adquirem a partir das vivências no seu cotidiano.

Sobre as características físicas, o livro estudado apresenta uma capa simples (Figura 1), cujas características principais são: predomínio das cores rosa e branca; apresentação de poucas informações escritas; e exibição de uma imagem contendo uma plataforma petrolífera. A impressão de todo o exemplar é de boa qualidade e os textos são grafados com fontes adequadas, possibilitando aos estudantes fazerem a distinção de títulos, subtítulos e conteúdos, 
os quais, em sua maioria, são escritos na mesma cor ou em cores semelhantes às do texto. Isso também acontece, por exemplo, com as estruturas dos compostos orgânicos exibidas, nas quais não são possíveis ser diferenciados os átomos de elementos químicos que deveriam estar bem destacados.

A apresentação e a discussão dos conteúdos são feitas de forma muito simplificada, o que acaba por descaracterizá-los, ou seja, ocasiona perda de significado dos assuntos diante do contexto e da vivência do aluno, contribuindo para o desenvolvimento de processos de ensino e aprendizagem desinteressantes e desestimulantes, o que leva à culminância de metodologias de ensino centradas quase sempre na simples memorização e, portanto, em uma aprendizagem ineficaz (NETO; FRACALANZA, 2003). Essa observação se estende por todos os capítulos do livro. Os autores deveriam ter explorado esses conteúdos de forma mais interativa e contextualizada, incluindo outros assuntos pertinentes à vida humana, como a bioquímica, os fármacos e o meio ambiente.

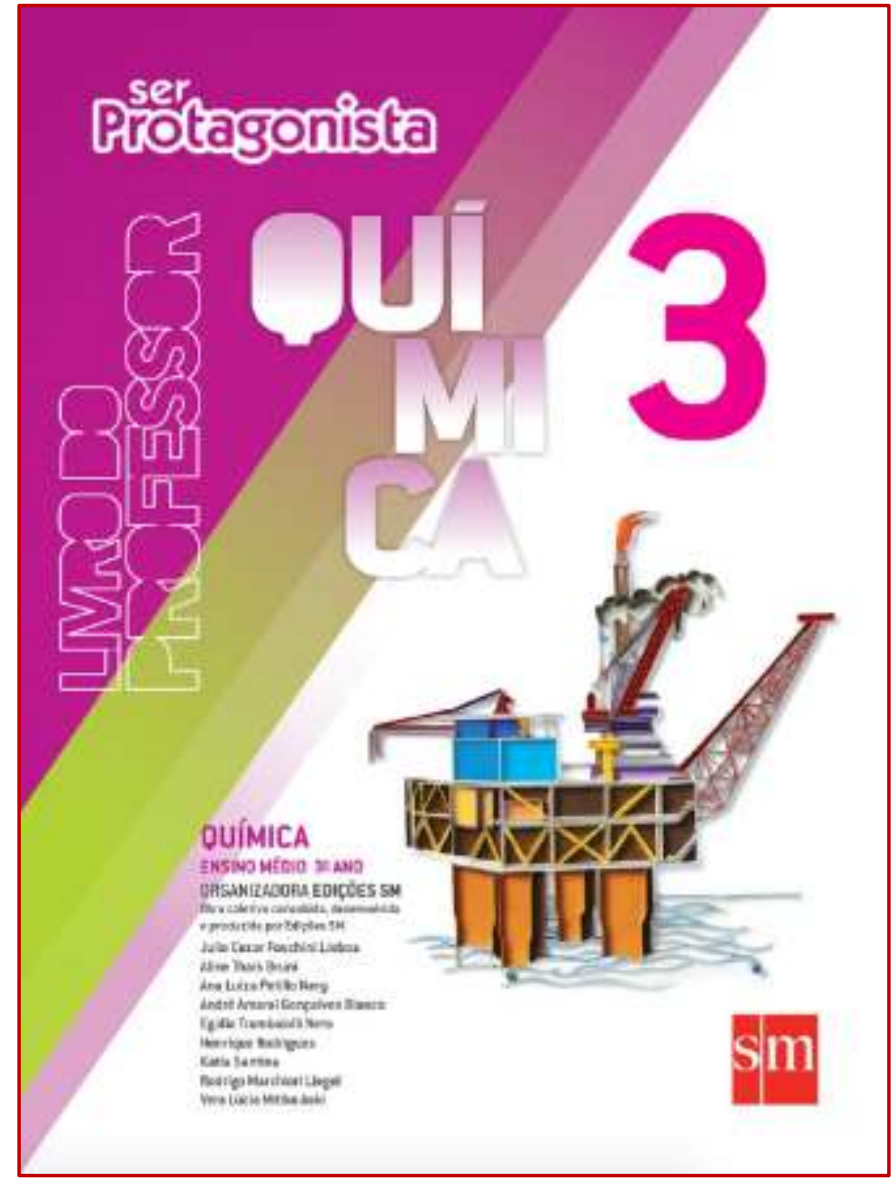

Figura 1 - Capa do volume 3 da Coleção 'Ser Protagonista Química'. (Fonte: Lisboa et al., 2014).

No que diz respeito à abrangência do conteúdo previsto pela escola, em geral, a realidade tem mostrado que os alunos da rede pública não conseguem estudar sequer a metade do conteúdo proposto pelo LD. Algumas justificativas para isso podem estar relacionadas ao fato da escola apresentar, em seu plano pedagógico, eventos e projetos extraclasses que interferem na carga horária da disciplina, ou ainda, especificamente no $3^{\circ}$ ano, quando os professores perdem muito tempo, por exemplo, reiterando o conteúdo referente à nomenclatura de compostos orgânicos (FERREIRA; DEL PINO, 2009). Devido a esses e vários outros motivos, muitos capítulos do livro analisado não chegam a ser abordados pelo professor durante o ano letivo.

A obra analisada foi publicada em 2014 e era a única edição disponível, até então, nas escolas da região onde este trabalho foi desenvolvido. Desse modo, os textos e as ilustrações apresentados datam de anos precedentes e muitas são referentes às décadas anteriores, podendo assim ser considerada uma obra já desatualizada, apesar dos conteúdos e das informações apresentarem coerência e veracidade em suas abordagens. Cabe ressaltarmos que essa desatualização se deve, em parte, à tecnologia dos meios de comunicação existentes na 
atualidade, que fazem as informações fluírem rapidamente. Reportando-se a esse aspecto, Santos (2006) destaca como uma das principais características que o LD deve apresentar, para atender as necessidades pedagógicas e de uma boa formação para professores e alunos, referese à precisão dos conteúdos, além de estarem corretos e atualizados sob o ponto de vista científico.

Outro aspecto relevante avaliado nesse livro diz respeito à linguagem utilizada pelos autores, a qual é de fundamental importância para a compreensão dos conteúdos científicos pelos estudantes. Nesse sentido, observamos que os textos são apresentados com uma linguagem rebuscada e complexa, não demonstrando adequabilidade ao tipo de leitor ao qual se destina e, dessa forma, dificultam o encadeamento lógico das ideias. Os capítulos são resumidos, com textos curtos e pouco explicativos, e incluem conceitos já 'prontos e acabados', bastando ao estudante apenas memorizá-los, sem necessidade de uma discussão. Isso acaba se configurando em uma metodologia tecnicista-tradicionalista, frequentemente incorporada pelos livros adotados atualmente, ou seja, o livro não abre espaço para o aluno refletir e discutir o conteúdo apresentado (CARNEIRO; SANTOS; MÓL, 2005).

Distribuídos em cinco unidades, os dezesseis capítulos seguem uma sequência didática com conteúdos que dão uma continuidade lógica e articulada ao anterior. No decorrer de todas as unidades e capítulos são exibidos imagens e textos explicativos que se complementam. Em sua maioria, eles retratam exemplos relacionados à sociedade brasileira e ao mundo. Contudo, não reportam à cultura local e nem a acontecimentos corriqueiros da vida dos estudantes, ignorando quase que completamente a contextualização dos conteúdos tão discutida pelas Orientações Educacionais Complementares aos Parâmetros Curriculares Nacionais (PCN+) (BRASIL, 2002).

Há várias figuras que compõem o volume analisado, quase sempre são imagens de objetos, produtos, reações e estruturas orgânicas que têm a finalidade de relacionar o conteúdo científico com exemplos e aplicações da vida cotidiana. Apesar de representarem situações que ocorrem habitualmente, a maioria está relacionada a uma região, um Estado, uma cidade ou a uma comunidade local específica dos alunos, ou seja, não abrange o cotidiano dos alunos brasileiros em geral. Além disso, nem sempre esses exemplos do cotidiano são devidamente explorados pelos autores, impossibilitando ao educando perceber o conhecimento químico de forma contextualizada e, consequentemente, comprometendo sua aprendizagem, a qual, muito provavelmente, resumir-se-á à memorização de conceitos e fórmulas.

Os textos e as ilustrações são organizados de forma coerente, ou seja, as ideias explicitadas por ambos os elementos apresentam conectividade. Em sua maioria, os textos são escritos ou elaborados com uma linguagem técnica, apresentando dificuldades na sua compreensão, já que não é familiar aos alunos. Em alguns de seus trechos, pudemos identificar a utilização equivocada do termo 'de forma análoga', como, por exemplo, no trecho "De forma análoga, a energia necessária para romper um mol de ligações triplas é menor do que a necessária para romper três mols de ligação simples" (LISBOA et al., 2014, p. 223), pois os autores comparam ideias bem distintas, haja visto o termo 'menor' usado por eles. No entanto, 
não nos foi possível assinalar erros ou omissões de termos, sejam eles comuns ou de natureza científica.

A última temática investigada está relacionada às atividades e aos exercícios propostos pelo livro. No fim de cada capítulo, são sugeridas atividades relativas ao conteúdo estudado. Em sua maioria, elas apresentam questões objetivas exigindo dos alunos um alto nível de conhecimento e interpretação. Além disso, também dependem de conhecimentos relacionados à Física, à Biologia e à Matemática para serem resolvidas de forma correta. No entanto, ressaltamos que, ao apresentar seus conteúdos, o livro não explora de maneira adequada os aspectos interdisciplinares necessários à resolução correta dessas atividades, ou seja, não aborda as conexões existentes entre os conhecimentos das disciplinas envolvidas no assunto estudado. Há ainda uma seção de atividades reproduzidas a partir de vestibulares e de provas do Exame Nacional do Ensino Médio (ENEM), com o objetivo de preparar os alunos para esses certames.

O livro não sugere atividades extraclasses, contudo todos os capítulos apresentam algumas seções intituladas 'Química tem história', 'Química e Biologia', 'Química e Física', 'Saiba mais' e 'Ação e cidadania'. Essas seções exploram textos informativos e curiosidades sobre os assuntos estudados em cada unidade, a fim de despertar o interesse dos alunos pelo conhecimento químico e de outras ciências.

Sobre a real contribuição desses exercícios para o trabalho do aluno e do professor, observamos que as atividades recomendadas em todos os capítulos favorecem o processo de reflexão, compreensão e apropriação do conhecimento pelo aluno. Além disso, permitem ao docente utilizá-las como ferramentas de avaliação dos conteúdos estudados. Porém, essas atividades precisam ser adequadas e atenciosamente exploradas, visando uma abordagem mais consistente para se atingir o objetivo esperado. Nessa perspectiva, vale ressaltar o pensamento de Stadler et al. (2012) para quem um eficiente LD não deve apresentar atividades didáticas que enfatizem exclusivamente aprendizagens mecânicas, fundamentadas na mera prática de memorização de fórmulas, nomes e regras.

Em se tratando de atividades para casa ou classe, a obra analisada não apresenta uma distribuição que contemple essa demanda. Elas estão dispostas de acordo com os conhecimentos propostos. Antes de serem apresentados os exercícios a serem solucionados, os autores expõem algumas questões já resolvidas, uma maneira de familiarizar os alunos com o tipo de perguntas que eles enfrentarão.

No fim de cada capítulo, é sugerida uma atividade experimental diretamente ligada ao conteúdo abordado. São experimentos simples e fáceis de serem realizados utilizando materiais alternativos. Isso possibilita aos estudantes reproduzi-los na própria sala de aula, oportunizando ao professor a realização de uma prática lúdica e diferenciada.

Com relação à identificação e à classificação dos recursos analógicos encontrados, foram consideradas analogias as partes do livro que estavam de acordo com a definição apresentada pelos pesquisadores da área (uma comparação entre características semelhantes de dois conceitos: um conhecido/análogo e outro desconhecido/alvo), ou quando detectamos a presença de expressões do tipo “... semelhante a ...", “... isso é como ...", “... fazendo uma 
analogia ...", “... analogamente ...", as quais, segundo os trabalhos estudados, indicam a presença de analogia (Tabela 1).

Tabela 1 - Dados numéricos relativos às analogias encontradas no volume 3 da coleção 'Ser Protagonista-Química'

\begin{tabular}{lccc}
\hline \multicolumn{1}{c}{ Conteúdo } & Capítulo & $\begin{array}{c}\text { Número de } \\
\text { analogias }\end{array}$ & $\begin{array}{c}\text { Frequência em } \\
\text { porcentagem }\end{array}$ \\
\hline Carbono e cadeias carbônicas & 1 & 02 & $22,2 \%$ \\
Isomeria óptica & 3 & 01 & $11,1 \%$ \\
Propriedades dos compostos de carbono & 10 & 01 & $11,1 \%$ \\
Reações envolvendo hidrocarbonetos & 11 & 04 & $44,5 \%$ \\
Reações envolvendo funções oxigenadas & 12 & 01 & $11,1 \%$ \\
\hline TOTAL & 5 & 09 & $100,0 \%$ \\
\hline
\end{tabular}

Fonte: elaborada pelos autores.

Assim, quanto ao primeiro critério de classificação (quantidade e frequência), o número de analogias encontradas foi muito pequeno. Apenas cinco capítulos do livro (em um total de 16) foram contemplados com nove analogias, sendo que uma grande parte dessas (quatro, correspondendo a $44,5 \%$ do total) estava presente somente no capítulo 11 . A maioria das analogias encontradas no livro (seis, correspondendo a $55,5 \%$ do total) estava localizada nos capítulos 10, 11 e 12, ou seja, essas estratégias pedagógicas estão distribuídas de maneira irregular ao longo do texto da obra.

No Quadro 1, apresentado na última página, estão retratados os resultados da análise dos outros critérios de classificação.

No que se refere ao critério da 'relação analógica', foi possível percebermos uma maior ocorrência de analogias do tipo 'funcional' (seis), sendo apenas três do tipo 'estrutural'. Os autores utilizaram os comportamentos funcionais de um composto orgânico para associá-los a outro composto, estabelecendo assim uma relação de similaridade entre eles. A maioria das analogias apresentam como conceitos análogos aqueles que tinham acabado de ser explorados pelos autores em conteúdos imediatamente anteriores, comprometendo o entendimento do conceito alvo, pois, caso o aluno não consiga assimilar o primeiro conceito, evidentemente também não compreenderá o segundo.

No critério 'apresentação', identificamos uma baixa frequência de analogias acompanhadas de ilustrações, apenas cinco são do tipo 'ilustrativo/verbal'. Quatro delas foram apresentadas apenas de forma escrita ('verbal'), o que pode dificultar a sua interpretação e compreensão do conceito alvo, contribuindo para a ineficiência da analogia. Representações visuais são importantes na compreensão da analogia, pois fundamentam a formação dos modelos mentais a partir da percepção e da imaginação. 
Em relação ao critério 'nível de abstração', frequentemente os autores utilizaram conceitos científicos para explicar ou compará-los a outros conceitos científicos também abstratos, provocando uma maior ocorrência de analogias do tipo 'abstrata/abstrata' (seis). As outras três foram classificadas como sendo do tipo 'concreto/abstrata'. Ao considerarmos que uma analogia demasiadamente abstrata se torna pouco familiar aos estudantes, ela pode não ser capaz de contribuir para a transposição das ideias similares de um fenômeno a outro.

Quanto à 'posição' na abordagem dos conteúdos, verificamos o predomínio de analogias apresentadas 'antes' (quatro) e 'durante' (quatro) a explicação do conceito alvo. Apenas uma foi considerada do tipo 'à margem'. Nos dois primeiros tipos, as analogias permitem estabelecer comparações mais diretas, pois, ao ser apresentado o conceito alvo, o aluno pode, simultaneamente, estabelecer as relações analógicas necessárias. Contudo, percebemos que as analogias encontradas nesse exemplar são apresentadas de forma muito sucinta, evidenciando um baixo potencial didático. A analogia situada 'à margem' das páginas do livro, ao lado do texto ao qual está relacionada, em geral pode passar despercebida pelo leitor, tornando sua presença improdutiva.

A presença de orientações 'pré-tópico' marca quase todos os raciocínios analógicos (oito) identificados. Com certeza, sem o emprego de expressões como 'de maneira análoga', 'de modo análogo', 'similar', 'semelhante', teríamos enfrentado dificuldades na classificação desse critério. A analogia sem pré-tópico só foi identificada graças à presença de ilustração complementando-a.

Quanto ao 'nível de enriquecimento', percebemos que oito das analogias se enquadram na categoria 'simples', devido ao compartilhamento de um único atributo entre os conceitos e à baixa similaridade entre eles. Apenas a quarta analogia pôde ser classificada como 'estendida', pois os autores utilizam dois conceitos análogos para explicar o conceito alvo. Quanto mais 'simples' for um raciocínio analógico, maior a possibilidade de ocorrer problemas na aprendizagem, visto que os alunos podem não perceber a relação existente entre os conceitos e, portanto, não a compreender. Nenhuma foi classificada como 'enriquecida'.

Um fato preocupante e comum, nesse e em outros LD, refere-se à quase inexistência de um 'mapeamento' das correspondências dos atributos comparados. No caso da obra investigada, das nove analogias nela identificadas, apenas uma (sétima) mostra um detalhamento tímido de correspondências entre os conceitos análogo e alvo, identificado pela presença do trecho "[...] ou seja, sofrem reação de adição, [...]" (LISBOA et al., 2014, p. 233).

Semelhantemente, a presença de discussões que abarcam o critério referente às 'limitações' das analogias é amiúde quase completamente ignorada pelos autores desse livro, ficando a cargo do professor o levantamento desses aspectos tão importantes para o sucesso da analogia. Somente na sétima analogia, apesar de não destacarem minuciosamente as características similares entre os domínios, ao expressarem "[...] apesar de não possuírem dupla-ligação [...]" (LISBOA et al., 2014, p. 233), os autores evidenciam um atributo não compartilhado pelos dois conceitos. Do mesmo modo, quando explicam que "[...] o mesmo não ocorre com cicloalcanos com cinco ou mais átomos de carbono em seu ciclo" (LISBOA et al., 2014, p. 233), evidencia-se a presença de uma limitação da analogia. 


\section{Considerações finais}

A partir da análise do volume 3 da coleção 'Ser Protagonista - Química', foi possível percebermos que essa obra apresenta várias deficiências quanto ao seu aspecto didáticoorganizacional. Os autores apresentam algumas características que não favorecem a aprendizagem apropriada do conteúdo, como por exemplo, capítulos resumidos, uso de uma linguagem complexa e pouco familiar aos estudantes, exemplos cotidianos que não se adequam à cultura local do aluno e a exposição de conceitos já prontos e acabados.

Essas constatações demonstram que se faz necessário intensificar as reflexões sobre a prática docente e as metodologias utilizadas pelo professor. O LD é uma ferramenta ainda muito utilizada em sala de aula, por isso a importância de se avaliar esse tipo de recurso e identificar as suas contribuições e possíveis obstáculos para os processos de ensino e aprendizagem.

Quanto às analogias presentes no livro analisado, percebemos que a frequência delas é pequena (apenas nove), em comparação ao número de capítulos que constituem a obra (dezesseis). Essas analogias não foram distribuídas de forma homogênea, sendo a maior concentração delas localizadas entre os capítulos 10 e 12. A baixa frequência desses instrumentos em uma obra que aborda conteúdos de Química Orgânica pode estar relacionada à falta de interesse dos autores em usar novas analogias, já que a grande maioria das utilizadas se referem àquelas que são usadas há décadas na maioria dos LD dessa área de estudo.

Aparentemente, percebemos que os autores não realizaram nenhum planejamento para o uso dessas analogias, já que elas foram apresentadas com o mínimo de precaução, sem explorar, de forma adequada, suas limitações. Além disso, eles não conseguiram retratar as analogias de modo que elas pudessem induzir o aluno ao interesse pelo conhecimento científico de maneira mais simplificada. Nesse sentido, destacamos que um dos principais aspectos a serem considerados na seleção e no uso de uma analogia é a capacidade de familiarização dos alunos com ela, ou seja, os alunos devem dominar a compreensão do análogo para compreenderem o conceito alvo.

Por fim, queremos destacar que a análise crítica e reflexiva, tanto dos aspectos organizacionais quanto das analogias presentes em um LD, seja de Química ou qualquer outra disciplina, faz-se necessária por ressaltar a importância da avaliação desses recursos didáticos, permitindo refletir sobre a eficácia e os prejuízos que eles podem causar ao sucesso da prática docente. Ao ser chamado na escola para participar do processo de escolha do LD, o professor deve ter a atitude de um avaliador profissional, de modo a não correr o risco de, ao final do processo, escolher um LD que não atenda às suas necessidades, de seus alunos e da escola, podendo comprometer a formação educacional de vários sujeitos.

\section{Referências}

ALMEIDA, H. A. DE. Las concepciones sobre analogías en el discurso de estudiantes de licenciatura en ciencias biológicas. Góndola, enseñanza y aprendizaje de las ciencias, Bogotá, v. 15, n. 1, p. 101-117, jan-abr. 2020. Disponível em: <https://revistas.udistrital.edu.co/index. php/GDLA/article/view/14401/15458>. Acesso em: 30 jan. 2020. 
BRASIL. Orientações Educacionais Complementares aos Parâmetros Curriculares Nacionais (PCN+) - Ciências da Natureza, Matemática e suas Tecnologias. Brasília: MEC, 2002. 141 p. Disponível em: <http://portal.mec.gov.br/seb/arquivos/pdf/CienciasNatureza.pdf>. Acesso em: 30 maio 2018.

BRASIL. Guia de livros didáticos: PNLD 2012: Química. Brasília: MEC, 2011. Disponível em: $<$ https://www.fnde.gov.br/index.php/centrais-de-conteudos/publicacoes/category/125guias?download=5513:pnld-2012-quimica>. Acesso em: 23 mar. 2020.

CARNEIRO, M. H. da S.; SANTOS, W. L. P. dos; MÓL, G. de S. Livro didático inovador e professores: uma tensão a ser vencida. Ensaio - Pesquisa em Educação em Ciências, Belo Horizonte, v. 7, n. 2, p. 101-113, maio-ago. 2005. Disponível em: <http://www.scielo.br/pdf/epec/v7n2/19832117-epec-7-02-00101.pdf>. Acesso em: 25 mar. 2019.

CURTIS, R. V.; REIGELUTH, C. M. The use of analogies in written text. Instructional Science, Amsterdam, v. 13, n. 2, p. 99-117, jul. 1984. Disponível em: <https://www.researchgate.net/profile/Charles_Reigeluth/publication/227005765_The_use_o f_analogies_in_written_text_26/links/0a85e5380ac229723d000000/The-use-of-analogies-inwritten-text-26.pdf>. Acesso em: 15 jan. 2018.

DIAS, A. F. P. Estudo das analogias presentes no livro didático 'Química na abordagem do cotidiano - vol. 1'. 2014, 52 f. Trabalho de Conclusão de Curso (Graduação em Química) Faculdade de Educação de Crateús, Universidade Estadual do Ceará, Crateús, 2014.

DUARTE, M. da C. Analogias na educação em ciências: Contributos e desafios. Investigações em Ensino de Ciências, Porto Alegre, v. 10, n. 1, p. 7-29, mar. 2005. Disponível em: <https://www.if.ufrgs.br/cref/ojs/index.php/ienci/article/download/520/317>. Acesso em: 16 fev. 2017.

DUIT, R. On the Role of Analogies and Metaphors in Learning Science. Science Education, New Jersey, v. 75, n. 6, p. 649-672, nov. 1991. Disponível em: <http://onlinelibrary.wiley.com/ doi/10.1002/sce.3730750606/full>. Acesso em: 06 jan. 2018.

FERREIRA, M.; DEL PINO, J. C. Estratégias para o ensino de química orgânica no nível médio: uma proposta curricular. Acta Scientiae, Canoas, v. 11, n. 1, p. 101-118, jan./jun. 2009. Disponível em: <https://www.lume.ufrgs.br/bitstream/handle/10183/143589/000709513.pdf?sequence=1 $>$. Acesso em: 10 out. 2018.

FRANÇA, A. M. de M. Estudo das analogias presentes nos volumes 1 e 2 da coleção 'Ser protagonista - Química'. 2017. 58 f. Trabalho de Conclusão de Curso (Graduação em Química) - Faculdade de Educação de Crateús, Universidade Estadual do Ceará, Crateús, 2017.

FRANCISCO JUNIOR, W. E. Analogias em livros didáticos química: um estudo das obras aprovadas pelo Plano Nacional do Livro Didático para o Ensino Médio 2007. Ciências \& Cognição, Rio de Janeiro, v. 14, n. 1, p. 121-143, mar. 2009. Disponível em: <http://pepsic.bvsalud.org/pdf/ cc/v14n1/v14n1a08.pdf>. Acesso em: 25 jan. 2018.

FREITAS, N. K.; RODRIGUES, M. H. O livro didático ao longo do tempo: a forma do conteúdo.

Revista da Pesquisa, Santa Catarina, v. 3, n. 1, p. 1-8, 2008. Disponível em: 
<http://www1.udesc.br/arquivos/portal_antigo/Seminario18/18SIC/PDF/074_Neli_Klix_Freita s. pdf>. Acesso em: 15 abr. 2018.

FRISON, M. D. et al. Livro didático como instrumento de apoio para construção de propostas de ensino de ciências naturais. In: ENCONTRO NACIONAL DE PESQUISA EM EDUCAÇÃO EM CIÊNCIAS, 7., 2009, Florianópolis, SC. Anais eletrônicos. Florianópolis, SC: ABRAPEC, 2009. Disponível em: <http://www.fep.if.usp.br/ profis/ arquivos/ viienpec/ VII\%20ENPEC\%20\%202009/www.foco. fae.ufmg. br/cd/pdfs/425.pdf>. Acesso em: 26 abr. 2018.

GeRHARDT, T. E.; SILVEIRA, D. T. (Orgs.). Métodos de Pesquisa, v. 1. Porto Alegre: Editora da UFRGS, 2009. $120 \mathrm{p}$.

LIMA, M. E. C. de C.; SILVA, P. S. Critérios que professores de química apontam como orientadores da escolha do livro didático. Ensaio - Pesquisa em Educação em Ciências, Belo Horizonte, v. 12, n. 2, p. 121-136, mai./ago. 2010. Disponível em: <http://www.scielo.br/ pdf/epec/v12n2/1983-2117-epec-12-02-00121.pdf>. Acesso em: 21 abr. 2018.

LISBOA et al. Ser Protagonista: Química, v. 3, 2. ed. São Paulo: Edições SM, 2014. 407 p.

MALHEIROS, B. T. Metodologia da pesquisa em educação. Rio de Janeiro: LTC, 2011.

MIRANDA, R. S.; LIMA, J. O. G. de L. A formação de professores e os saberes docentes na seleção do livro didático de biologia: o estado da questão. Revista da SBEnBio, Niterói, n. 9, p. 37283738, jul. 2016. Disponível em: <https://sbenbio.org.br/wp-content/uploads/edicoes/ revista_sbenbio_n9.pdf >. Acesso em: 17 mar. 2017.

MÓL, G. de S. O uso de analogias no ensino de Química. 1999, 198 f. Tese (Doutorado em Química) - Programa de Pós-Graduação em Ensino de Ciências, Universidade de Brasília, Brasília, DF, 1999.

MONTEIRO, I. G.; JUSTI, R. S. Analogias em livros didáticos de química brasileiros destinados ao ensino médio. Investigações em Ensino de Ciências, Porto Alegre, v. 5, n. 2, p. 67-91, 2000. Disponível em: <https://www.if.ufrgs.br/cref/ojs/index.php/ienci/article/view/650/441>. Acesso em: 10 fev. 2018.

MORTIMER, E. F. A evolução dos livros didáticos de Química destinados ao Ensino Secundário. Em aberto, Brasília, v. 7, n. 40, p. 25-41, out./dez. 1988. Disponível em: <http://www.emaberto.inep.gov.br/index.php/emaberto/article/viewFile/1721/1692>. Acesso em: 15 fev. 2018.

NETO, J. M.; FRACALANZA, H. O livro didático de ciências: problemas e soluções. Ciências \& Educação, Bauru, v. 9, n. 2, p. 147-157, 2003. Disponível em: <http://www.scielo.br/ pdf/ciedu/v9n2/01.pdf>. Acesso em: 29 jan. 2019.

SANTOS, S. M. de O. Critérios para avaliação de livros didáticos de química para o ensino médio. 2006, 195 f. Dissertação (Mestrado em Ensino de Ciências) - Programa de PósGraduação em Ensino de Ciências, Universidade de Brasília, Brasília, 2006. Disponível em: <http://repositorio.unb.br/bitstream/10482/3745/1/2006_Sandra\%20Maria\%20de\%20Oliveir a\%20Santos.pdf>. Acesso em: 03 mar. 2018. 
STADLER, J. P. et al. Análise de obstáculos epistemológicos em livros didáticos de química do ensino médio PNLD 2012. Holos, Natal, v. 2, n. 28, p. 234-243, 2012. Disponível em: <http://www.redalyc.org/pdf/4815/4815492650 20.pdf>. Acesso em: 10 mar. 2018.

THIELE, R. B.; TREAGUST, D. F. The nature and extent of analogies in secondary chemistry textbooks. Instructional Science, Wellington, v. 22, n. 1, p. 61-74, 1994. Disponível em: <https://link.springer.com/article/10.1007/BF00889523>. Acesso em: 02 jan. 2018. 
Quadro 1 - Demais critérios de classificação das analogias encontradas no volume 3 da coleção 'Ser Protagonista - Química'

\begin{tabular}{|c|c|c|c|c|c|c|c|c|c|c|c|}
\hline$\frac{\frac{0}{3}}{\frac{\pi}{2}}$ & $\begin{array}{l}\frac{\pi}{00} \\
\frac{0}{\pi} \\
\frac{1}{\pi} \\
\text { 일 }\end{array}$ & Conteúdo & Conceitos comparados (analogia-alvo) & $\begin{array}{c}\text { Relação } \\
\text { analógica }\end{array}$ & 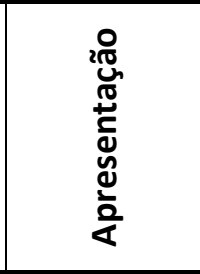 & $\begin{array}{l}\text { Nível de } \\
\text { abstração }\end{array}$ & $\frac{20}{20}$ & 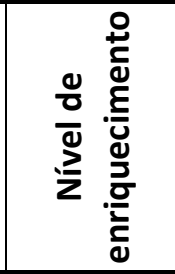 & 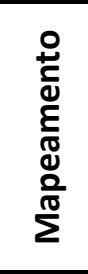 & 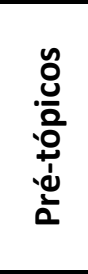 & 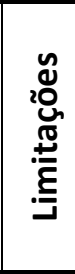 \\
\hline \multirow{2}{*}{1} & 1 & \multirow{2}{*}{$\begin{array}{l}\text { Carbono e cadeias } \\
\text { carbônicas }\end{array}$} & $\begin{array}{l}\text { Estrutura do Carbono primário - Estrutura do } \\
\text { carbono terciário }\end{array}$ & Estrutural & $\begin{array}{c}\text { Ilustrativo/ } \\
\text { verbal }\end{array}$ & $\begin{array}{l}\text { Abstrato/ } \\
\text { abstrato }\end{array}$ & Antes & Simples & Não & Sim & Não \\
\hline & 2 & & $\begin{array}{l}\text { Classificação dos compostos de cadeia } \\
\text { aberta- Compostos de cadeia cíclica alifática }\end{array}$ & Estrutural & $\begin{array}{c}\text { Ilustrativo/ } \\
\text { verbal }\end{array}$ & $\begin{array}{l}\text { Abstrato/ } \\
\text { abstrato }\end{array}$ & Durante & Simples & Não & Sim & Não \\
\hline 3 & 3 & Isomeria óptica & $\begin{array}{l}\text { Sobreposição do objeto e imagem (mãos) - } \\
\text { Assimetria }\end{array}$ & Funcional & $\begin{array}{c}\text { Ilustrativo/ } \\
\text { verbal }\end{array}$ & $\begin{array}{c}\text { Concreto/ } \\
\text { abstrato }\end{array}$ & À margem & Simples & Não & Não & Não \\
\hline 10 & 4 & \begin{tabular}{|lr} 
Propriedades & dos \\
compostos & de \\
carbono & \\
\end{tabular} & $\begin{array}{l}\text { Formato da bola de futebol e do domo } \\
\text { geodésico - Estrutura da molécula do } \\
\text { Fulereno }\end{array}$ & Funcional & $\begin{array}{l}\text { Ilustrativo/ } \\
\text { verbal }\end{array}$ & $\begin{array}{l}\text { Concreto/ } \\
\text { abstrato }\end{array}$ & Durante & Estendida & Não & Sim & Não \\
\hline \multirow{4}{*}{11} & 5 & \multirow{4}{*}{$\begin{array}{l}\text { Reações } \\
\text { envolvendo } \\
\text { hidrocarbonetos }\end{array}$} & $\begin{array}{l}\text { Reação dos alcanos com ácido nítrico } \\
\text { concentrado - reação dos alcanos com ácido } \\
\text { sulfúrico concentrado }\end{array}$ & Funcional & Verbal & $\begin{array}{l}\text { Abstrato/ } \\
\text { abstrato }\end{array}$ & Antes & Simples & Não & Sim & Não \\
\hline & 6 & & $\begin{array}{l}\text { Energia para romper ligações duplas e } \\
\text { simples - Energia para romper ligações triplas }\end{array}$ & Funcional & Verbal & $\begin{array}{l}\text { Abstrato/ } \\
\text { abstrato }\end{array}$ & Antes & Simples & Não & Sim & Não \\
\hline & 7 & & $\begin{array}{l}\text { Reação de adição nos alcenos - Cicloalcanos } \\
\text { formados por três e quatro carbonos }\end{array}$ & Funcional & Verbal & $\begin{array}{c}\text { Abstrato/a } \\
\text { bstrato }\end{array}$ & Durante & Simples & Sim & Sim & Sim \\
\hline & 8 & & $\begin{array}{l}\text { Reação de ciclopentano com o bromo }\left(\mathrm{Br}_{2}\right) \text { - } \\
\text { reação de ciclo-hexano com o cloro }\left(\mathrm{Cl}_{2}\right)\end{array}$ & Funcional & $\begin{array}{c}\text { Ilustrativo/ } \\
\text { verbal }\end{array}$ & $\begin{array}{l}\text { Abstrato/ } \\
\text { abstrato }\end{array}$ & Antes & Simples & Não & Sim & Não \\
\hline 12 & 9 & $\begin{array}{l}\text { Reações de } \\
\text { compostos } \\
\text { oxigenados }\end{array}$ & $\begin{array}{l}\text { Nome dos catalisadores (éteres de coroa) - } \\
\text { semelhança a uma coroa }\end{array}$ & Estrutural & Verbal & $\begin{array}{l}\text { Concreto/ } \\
\text { abstrato }\end{array}$ & Durante & Simples & Não & Sim & Não \\
\hline
\end{tabular}

